\title{
Differential Action of Anti-CD20 Monoclonal Antibodies: Role in Induction of Cell Death
}

\section{Vijay Singh ${ }^{1,2}$ and Damodar Gupta ${ }^{1 *}$}

${ }^{1}$ Department of Capacity Enhancement and Product Induction, Institute of Nuclear Medicine and Allied Sciences, Brig. SK Mazumdar Marg, Timarpur, Delhi, India ${ }^{2}$ Applied Entomology and Radiation Biology Lab, Department of Zoology (North Campus), University of Delhi, Delhi, India

\begin{abstract}
Purpose: To study and assess to the sensitivity of Burkitt's lymphoma cells harboring differential levels of cell surface CD20 for anti-CD20 monoclonal Antibodies.

Material and methods: Burkitt's lymphoma cell line 'Daudi' was used during present study. Cells were exposed to single dose of $y$-radiation $(0.5 \mathrm{~Gy})$ and thereafter incubated with rituximab (Rtx) or tositumomab (Tst) $(0.5 \mu \mathrm{g} /$ $\mathrm{ml}$ concentration each). The changes in expression of RelA, Akt and Bax/Bcl-2 ratio was measured to assess sensitivity of cells in term of cell death.

Results: During the present investigation, we found that cells incubated with anti-CD20 mAbs at +20 hrs post radiation exposure showed higher levels of cell death in term of Bax/Bcl-2 ratio. In addition, we also found the significant changes in expression of pro-survival signaling proteins such as RelA and Akt pathways. Moreover, we found that tositumomab is a potent inducer of apoptotic cell death.

Conclusion: These findings suggested that the efficacy of anti-CD20 mAbs depends on the number of CD20 molecules expressed on cell surface and type of antibody used. It may provide new treatment options for selection of anti-CD20 mAbs even in aggressive B-cell lymphoma, which harbors low levels of CD20 or even resistant to current therapies in vivo.
\end{abstract}

Keywords: Ionizing radiation; CD20; ROS; Bax/Bcl-2; Cell death

Abbreviations: IR: Ionizing Radiation; BL: Burkitt's Lymphoma; Rtx: Rituximab; Tst: Tositumomab; mAbs: Monoclonal Antibodies

\section{Introduction}

Burkitt's lymphoma (BL) is a highly aggressive form of B-cell associated cancer with the majority of patients younger than 40 years and one-third are at adolescent and young adult age. In modern days chemotherapy protocols achieve overall events free survival rates of nearly $90 \%$; however, they are facing with the challenge of relapse. In addition, the use of anti-CD20 monoclonal antibodies holds great promise for improving long-term curative outcomes while diminishing acute and long-term toxicities. However, in clinical applications, the efficacy of therapy using CD20 mAbs creates resistance, affecting the long-term survival for patients with relapsed or refractory disease. The explanation for this therapeutic resistance is not clear. Although, some investigators reported that decreased $\mathrm{CD} 20$ expression and/ or low levels of CD20 on the surface of malignant B-cells is one of the major contributing factors and respond proportionally less well to rituximab and other mAbs [1-5]. CD20, an non-glycosylated transmembrane protein exclusively expressed on B-cells, appears during the pre- $\mathrm{B}$ cell stage, however its absent during the earlier or later stages of B-cell differentiation such as antibody-secreting plasma cells. The binding of anti-CD20 mAbs with CD20 cause intracellular oxidative stress, simultaneously inducing activation of members of the $\operatorname{Src}$ family of tyrosine kinases, elevation in intracellular $\mathrm{Ca}^{2+}$, phospholipase $\mathrm{C} \gamma$ activation, collectively leading to apoptosis [6-8]. Apoptosis is a tightly regulated process of cell death, which triggered by caspasedependent or independent manner and controlled by the interplay of a number of positive and negative regulatory proteins such as Bax and Bcl-2 family members [9-13]. Moreover, anti-CD20 mAbs have an ability to modulate major pro-survival pathways such as ERK1/2 MAPK, NF- $\mathrm{BB}$ and Akt, which directly or indirectly controlled proapoptotic and anti-apoptotic machinery [14-16]. Thus, the changes in CD20 levels on malignant B-cells would be a new treatment option for cancer prevention. In our previous study, we determined that the cells exposed to sub-lethal dose of $\gamma$-radiation $(0.5 \mathrm{~Gy})$ could induce $\sim 3 \pm 0.5$-fold changes CD20 levels in Burkitt's lymphoma cell line 'Daudi. It was associated with changes in oxidative condition in the intracellular milieu and determined anti-CD20 mAbs mediated cell death $[6,17]$. Based on our previous findings, we hypothesized that cells treated with anti-CD20 mAbs just after exposure to a sub-lethal dose of $\gamma$-radiation might improve antibody-mediated cell death. During present investigation, we found higher level of induction of cell death in association with differential levels of CD20 expression in term of Bax/ Bcl-2 ratio and simultaneously significant reduce expression of prosurvival pathways such as RelA and Akt, which directly or indirectly control Bax/Bcl-2.

\section{Materials and Methods}

RPMI-1640, Penicillin G potassium salt, streptomycin, N-2Hydroxyethyl piperazine N-2-Ethane sulphonic acid sodium (HEPES sodium), Dimethyl sulfoxide (DMSO), sodium pyruvate, Bradford reagent, Protease and Phosphatase Inhibitor Cocktail were obtained

*Corresponding author: Dr. Damodar Gupta, Scientist 'E', Department of Capacity Enhancement and Product Induction, Institute of Nuclear Medicine and Allied Sciences, Brig. SK Mazumdar Marg, Timarpur, Delhi-110054 India, Tel: 011 23905370; Email: damodar.gupta@gmail.com

Received February 22, 2018; Accepted March 26, 2018; Published March 28 2018

Citation: Singh V, Gupta D (2018) Differential Action of Anti-CD20 Monoclonal Antibodies: Role in Induction of Cell Death. J Cancer Sci Ther 10: 064-068. doi: 10.4172/1948-5956.1000519

Copyright: $\odot 2018$ Gupta D, et al. This is an open-access article distributed under the terms of the Creative Commons Attribution License, which permits unrestricted use, distribution, and reproduction in any medium, provided the original author and source are credited. 
from Sigma-Aldrich Chemicals (St. Louis, MO, USA). Fetal bovine serum (FBS) was obtained from Invitrogen (USA). Anti-CD20 chimeric antibodies, such as rituximab (Rtx) were obtained from Genentech (Genentech, Inc., South San Francisco, CA), and tositumomab (Tst) from Corixa (Corixa Corporation Seattle, WA). All other chemical were used of AR grade and obtained from local manufacturers, SRL and Himedia India. Cell culture and biochemical purpose related plastic wares were obtained from BD Bioscience (USA), Corning (USA) and Tarsons, India.

\section{Cell culture}

Daudi cells were obtained from the American type culture collection; (USA) and culture was maintained in RPMI 1640 media supplemented with $10 \%$ fetal bovine serum, 10 mM HEPES, 50 units/ $\mathrm{ml}$ penicillin, $50 \mu \mathrm{g} / \mathrm{ml}$ streptomycin and $1 \%$ non-essential amino acids at $37^{\circ} \mathrm{C}$ in a humid atmosphere with $95 \%$ air and $5 \% \mathrm{CO}_{2}$.

\section{Irradiation and treatment of cells}

Exponentially growing cells were exposed to $\gamma$-radiation, $0.5 \mathrm{~Gy}$ and 1.5 Gy separately using the ${ }^{60} \mathrm{Co}$-teletherapy unit (BhabhatronII Telecobalt unit; obtained from Bhabha Atomic Research Center, Mumbai, India) at a dose rate of $1.67 \mathrm{~Gy} / \mathrm{min}$. Further, cells were incubated with Rtx or Tst $(5 \mu \mathrm{g} / \mathrm{ml})$ at $+20 \mathrm{hrs}$ post-radiation exposure. Control groups were treated similarly except for irradiation.

\section{Protein isolation and estimation}

Briefly, cells were collected using centrifugation at $1000 \mathrm{rpm}$ in ice-cold condition and washed with phosphate buffer saline ( $\mathrm{pH}$ 7.4). The cell palate were lysed in radioimmunoprecipitation assay buffer (50 mM Tris- $\mathrm{HCl} \mathrm{pH} \mathrm{7.4,} 150 \mathrm{mM} \mathrm{NaCl}, 0.5 \%$ Sodium deoxycholate, 0.1\% SDS, $1 \%$ Nonidat-P40, 5 mM EDTA, 1 mM EGTA, 1 mM PMSF, protease and phosphatase inhibitor cocktails) using vigorous vortexing as previously described method [6]. Samples were centrifuged at 10,000 $\mathrm{rpm}$ at $4^{\circ} \mathrm{C}$ and carefully supernatant containing soluble proteins were transferred in fresh vials. Protein concentration was measured of each sample by Bradford method [18] using bovine serum albumin (BSA) as a standard. The samples were prepared with $4 \mathrm{x}$ SDS sample buffer (1x equals 31.25 mM Tris- $\mathrm{HCl}$ (pH 6.8), 2\% SDS, 5\% 2-mercaptoethanol, and $0.005 \%$ bromophenol blue) and heated for $5 \mathrm{~min}$ at $95^{\circ} \mathrm{C}$.

\section{Western blotting}

To determine the changes in expression of Bax/Bcl-2 protein levels and pro-survival signaling pathway's protein (RelA and Akt) were measured as previously described method [6]. Equal amounts of protein $(60 \mu \mathrm{g} / \mathrm{sample})$ from each sample were loaded in $12 \%$ SDS poly-acrylamide gel. A standard molecular weight marker (BioRad, USA) was loaded in a separate well parallel to the samples. Initially, 40 volts of current was supplied for the formation of protein stack. Thereafter, it was constant run at 100 volts and proteins were resolved in the denaturating gel. After complete resolution, proteins were transferred from SDS poly-acrylamide gel on to a nitrocellulose membrane. The membranes were blocked in blocking buffer (3\% BSA prepared in tris buffer saline with $0.1 \%$ Tween-20) for $1 \mathrm{hr}$ at room temperature. Thereafter, membranes were incubated overnight at $4^{\circ} \mathrm{C}$ with anti-RelA; 1:1500, anti-Akt; 1:1000, anti-Bcl-2; 1:2000 and antiBax; 1:1500. After incubation, membrane was washed and incubated with corresponding horseradish peroxidase-conjugated secondary antibodies (Sigma, St. Louis, MO, USA) for $3 \mathrm{hrs}$ at room temperature. Thereafter, membranes were washed, and protein bands were visualized using enhanced ECL chemiluminescence Pico. $\beta$-actin was used to ensure equal loading of protein samples. The intensity of bands was determined using GS- $900^{\text {mix }}$ Calibrated Densitometer software. The results were expressed as fold changes from mean of densitometer data \pm SD of three independent experiments.

\section{Data Analysis and Statistical Evaluations}

Assays were set up in triplicates and the results were expressed as the mean $\pm \mathrm{SD}$. The significant changes were analyzed by one-way ANOVA and $p$ values were shown at different levels of significance $(\mathrm{p}<0.05, \mathrm{p}<0.01, \mathrm{p}<0.001)$.

\section{Results}

\section{Preparation of protein samples}

Equal amount of protein samples were used for immune-blotting to determine precise changes in expression of genes or changes in protein levels. The preparation of the sample for western blotting, protein concentration in each sample was measured using Bradford method. The proteins concentration in each sample were determined

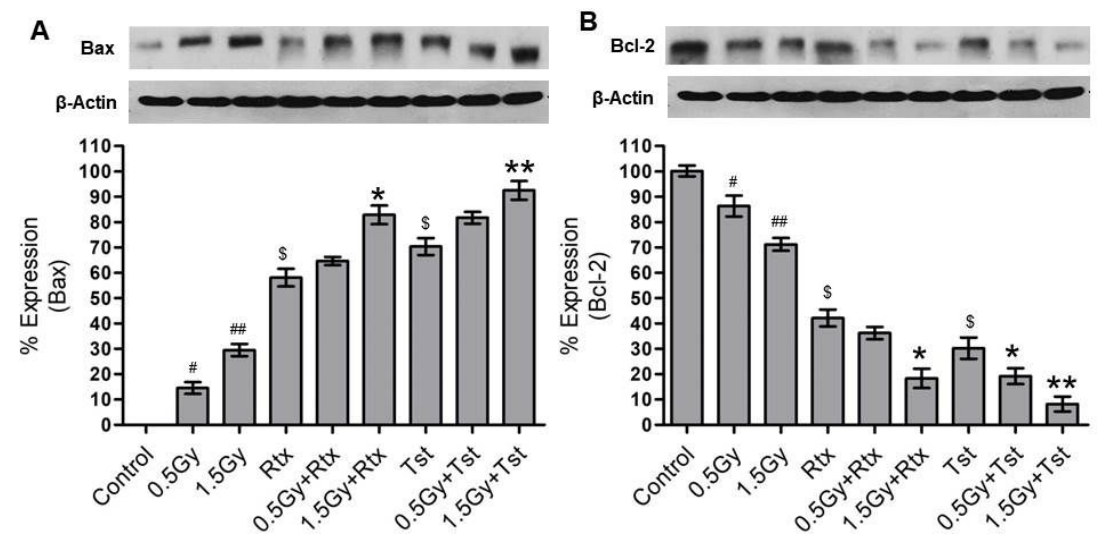

Figure 1: The changes in ration of $\mathrm{Bcl}-2 / \mathrm{Bax}$ expression. (A) Bcl-2 and Bax expression were measured using immunoblot. (B) The percent changes in Bcl-2 expression was measured from densitometry mean \pm SD and statistical analysis was performed using ONE-way ANOVA. Significant values represented as; \#p<0.05 for $0.5 \mathrm{~Gy}$ vs control, \#\#p<0.01 for $1.5 \mathrm{~Gy}$ vs control, $\$ p<0.001$ for Rtx or Tst vs control, * $<<0.05$ for Rtx vs $1.5 \mathrm{~Gy}+\mathrm{Rtx}$ or Tst vs $1.5 \mathrm{~Gy}+\mathrm{Tst}$. (B) Bax is a pro-apoptotic protein. The percent changes in Bax expression was measured from densitometry mean \pm SD and statistical analysis was performed using ONE-way ANOVA. Significant values represented as; \#p<0.05 for control vs $0.5 \mathrm{~Gy}$, \#p<0.01 for control vs $1.5 \mathrm{~Gy}, \$ p<0.05$ for control vs Rtx or Tst, ${ }^{*} p<0.05$ for Rtx vs $1.5 \mathrm{~Gy}+\mathrm{Rtx}$ and ** $\mathrm{p}<0.01$ for Tst vs $1.5 \mathrm{~Gy}+\mathrm{Tst}$. 

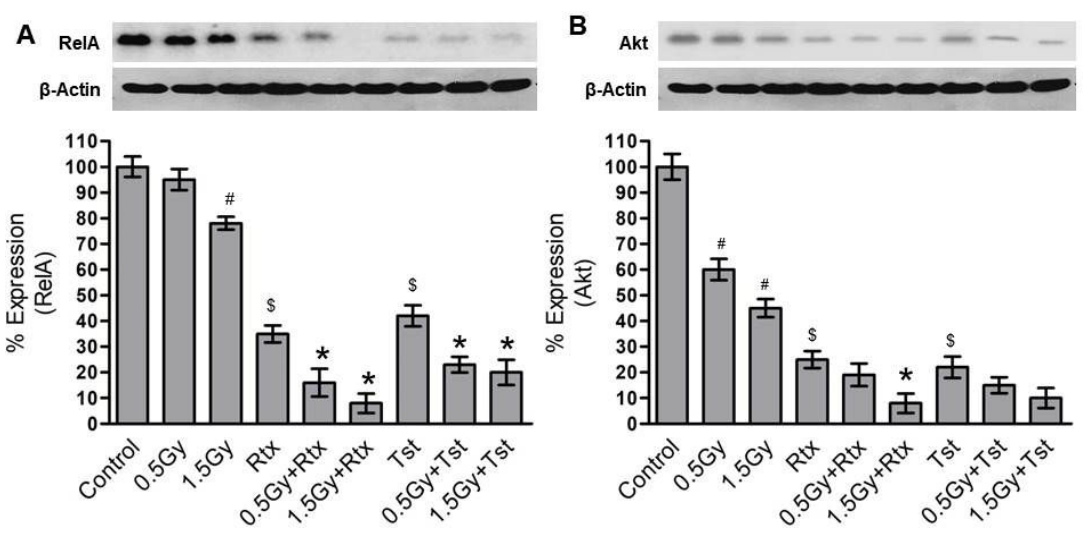

Figure 2: Measurement the anti-CD20 mAbs induced changes the expression of RelA and Akt proteins using western blotting. (A) RelA is a widely accepted pro-survival signaling protein. The percent changes in RelA (p65) expression was measured from densitometry mean \pm SD and statistical analysis was performed using ONE-way ANOVA. Significant values are represented as; \#p<0.05 for control vs $1.5 \mathrm{~Gy}, \$ p<0.001$ for control vs Rtx or Tst, * $p<0.05$ for Rtx vs $0.5 \mathrm{~Gy}+\mathrm{Rtx}$ or $1.5 \mathrm{~Gy}+\mathrm{Rtx}$, ${ }^{*} \mathrm{p}<0.05$ for Tst vs $0.5 \mathrm{~Gy}+\mathrm{Tst}$ or $1.5 \mathrm{~Gy}+\mathrm{Tst}$. (B) Akt is a prominent anti-apoptotic signaling pathway. The percent changes in Akt expression was measured from densitometry mean $\pm \mathrm{SD}$ and statistical analysis was performed using ONE-way ANOVA. Significant values are represented as; \#p<0.05 for control vs $0.5 \mathrm{~Gy}$ or $1.5 \mathrm{~Gy}$, $\$ \mathrm{p}<0.001$ for control vs Rtx or Tst, * $\mathrm{p}<0.05$ for Rtx vs $1.5 \mathrm{~Gy}+\mathrm{Rtx}$.

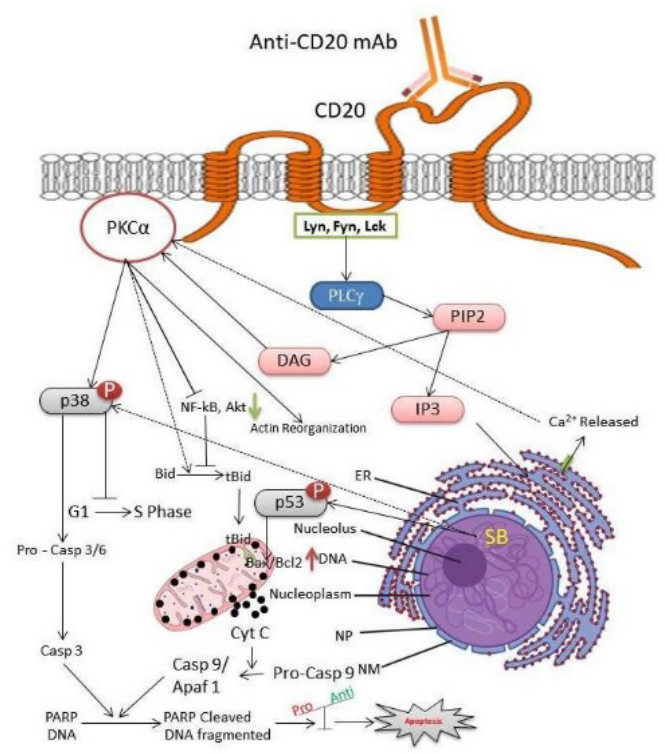

Figure 3: Anti-CD20 mAbs-induced cell death process. Schematic diagram illustrating the proposed possible cell death pathway evoked by type I anti-CD20 mAbs (Rtx) and type I anti-CD20 mAbs (Tst) in association with differential levels of CD20. . *SB=Strand Break.

using bovine serum albumin (BSA) standard curve as 1 OD considered equivalent to $8.5 \mu \mathrm{g}$ protein.

\section{Western blotting}

Here, we measured the anti-CD20 mAbs induced attenuated expression of pro-apoptotic and anti-apoptotic gene products such as Bax and Bcl-2 respectively in association with changes in $\mathrm{CD} 20$ levels and also measured changes in the expression of RelA and Akt levels. As shown in Figure 1A, significant changes in expression of Bax was observed in cells exposed to $0.5 \mathrm{~Gy}$ or $1.5 \mathrm{~Gy}$ and in cells treated either Rtx or Tst with or without radiation. The expression of Bax in control sample was considered as zero percent change in expression (Figure 1A). The up-regulation of Bax expression was observed $14 \pm$ 2.2 percent in cells exposed with 0.5 Gy and $29 \pm 2.4$ percent in 1.5 Gy irradiated cells with respect to sham-irradiated control. In addition, cell incubated with anti-CD20 mAbs, Bax expression was also found to be significantly higher, $58 \pm 3.5$ percent changes in Bax expression was determined in Rtx treated cells and $70 \pm 3.3$ percent changes in Tst treated cells. Moreover, the significant changes Bax expression was also observed in cells treated with Rtx or Tst at +20 hrs post radiation exposure (0.5 Gy, 1.5 Gy). Approximately $64 \pm 1.5$ percent was observed in the $0.5 \mathrm{~Gy}+\mathrm{Rtx}$ group and $82 \pm 3.7$ percent in $1.5 \mathrm{~Gy}+\mathrm{Rtx}$ treated groups as compared to Rtx treated alone group. Moreover, we also observed $81 \pm 2.3$ percent changes in $0.5 \mathrm{~Gy}+\mathrm{Tst}$ and $92 \pm 3.7$ percent in $1.5 \mathrm{~Gy}+\mathrm{Tst}$ treated groups as compared to Tst treated alone group. Besides measuring the up-regulation of Bax expression, the down-regulation of $\mathrm{Bcl}-2$ expression was also observed. The changes in Bcl-2 expression were found to be significantly higher as dosedependent manner and also in the treatment of cells with anti-CD20 $\mathrm{mAbs}$ alone or in a combination with anti-CD20 mAbs + IR (Figure 1B). The cells were exposed to $0.5 \mathrm{~Gy}$ or $1.5 \mathrm{~Gy}$, the changes in Bcl-2 expression was found to be as $14 \pm 4.1$ percent and $29 \pm 2.5$ percent with respect to sham-irradiated control respectively. In addition, cells treated with Rtx or Tst alone, Bcl-2 expression was found to be $58 \pm$ 3.3 percent changes in Rtx and $70 \pm 4.2$ percent changes in Tst treated group with respect to untreated control. Moreover, cells treated with Rtx at 20 hrs post radiation exposure $(0.5 \mathrm{~Gy}$ or $1.5 \mathrm{~Gy})$ were also found to be significant as $64 \pm 2.4$ percent changes in $0.5 \mathrm{~Gy}+\mathrm{Rtx}$ and $82 \pm 3.8$ percent changes in the $1.5 \mathrm{~Gy}+\mathrm{R}$ tx group as compared to Rtx treated alone. Cells treated with Tst at +20 hrs post $0.5 \mathrm{~Gy}$ or $1.5 \mathrm{~Gy}$ radiation exposure also showed $81 \pm 3.1$ percent changes in $0.5 \mathrm{~Gy}+\mathrm{Tst}$ treated group and $92 \pm 2.8$ percent changes in $1.5 \mathrm{~Gy}+$ Tst treated group as compared to Tst treated alone group. We, further investigated Rtx or Tst mediated activation of pro-survival signaling pathways that regulate these gene products. During present study we found that Rtx and Tst have ability to down-regulate RelA (NF-kB family's protein) and Akt pro-survival signaling pathways which participate in regulation of Bax and Bcl-2 expression (Figures $2 \mathrm{~A}$ and $2 \mathrm{~B}$ ). During present investigation the changes in expression of RelA (NF-kB family's protein) were determined followed by Rtx and Tst treatment or in combination with IR (Figure 2A). Our observation revealed that cells treated with Rtx and Tst separately showed significant changes in expression of RelA such as $65 \pm 3.3$ percent changes in Rtx and $58 \pm 4.1$ percent changes in Tst treated cells with respect to un-treated control. Interestingly, cells treated with Rtx or Tst at $+20 \mathrm{hrs}$ post radiation exposure $(0.5$ Gy or 1.5 Gy) showed $83 \pm 5.4$ percent changes in 0.5 
$\mathrm{Gy}+\mathrm{Rtx}$ and $77 \pm 3.1$ percent changes in $0.5 \mathrm{~Gy}+\mathrm{Tst}$ treated group as compared to control. Moreover, cells treated with Rtx or Tst at $+20 \mathrm{hrs}$ post 1.5 Gy radiation exposure showed $92 \pm 3.8$ percent and $80 \pm 4.9$ percent changes in RelA expression respectively. Beside the changes in expression of RelA, the changes in expression of Akt were also found to be significant with respect to untreated control (Figure 2B). As shown in Figure 2B, cells exposed to 0.5 Gy or 1.5 Gy showed $40 \pm 4.1$ percent and $55 \pm 3.5$ percent changes in Akt expression with respect to control. Interestingly, Cells treated with Rtx at $+20 \mathrm{hrs}$ post radiation exposure ( 0.5 Gy or $1.5 \mathrm{~Gy}$ ) showed $81 \pm 4.4$ percent changes in $0.5 \mathrm{~Gy}+\mathrm{Rtx}$ and $92 \pm 3.8$ percent changes in $1.5 \mathrm{~Gy}+\mathrm{R}$ tx treated group with respect to untreated control. Moreover, Cells treated with Tst at +20 hrs post 0.5 Gy or 1.5 Gy radiation exposure showed $85 \pm 3.1$ percent and $90 \pm$ 3.9 percent changes in Akt expression respectively. In addition, cells treated with Rtx or Tst alone showed $75 \pm 3.3$ percent changes and $78 \pm$ 3.9 percent changes respectively.

\section{Discussion}

Modulation in levels of CD20 on the cell surface and antibody engineering are current trends to enhance the efficacy of cancer therapy $[3,19]$. In our previous study, we investigated radiation-induced changes of CD20 surface levels which may play a crucial and central role in determining the relative efficacy of Rtx and Tst $\mathrm{mAbs}$ in treating Burkitt's lymphoma disease. We have examined the $\gamma$-radiationinduced modulation of CD20 levels on the cell surface of the Burkitt's lymphoma cell line 'Daudi' [6]. Cells exposed with a sub-lethal dose of $\gamma$-radiation ( $0.5 \mathrm{~Gy}$ ) showed significant increas in CD20 expression as time-dependent manner and it was associated with changes in redox status in intracellular milieu $[6,20]$. In correlation to previous findings, here we determined the relative efficacy of anti-CD20 mAbs at differential levels of CD20 expression, Cells treated with Rtx and Tst $\mathrm{mAbs}$, at +20 hrs post radiation exposure showed significant induced cell death in combination with radiation and mAbs as compared to antibodies treated alone. Interestingly, Tst was found to be a potent inducer of cell death as compared to Rtx.

During present investigations, we studied the changes in expression of the pro-apoptotic member such as Bax and the antiapoptotic member such as Bcl-2 induced by anti-CD20 mAbs mediated at differential levels of CD20 (Figures 1A and 1B). The members of the Bcl-2 family are a group of crucial regulatory factors in apoptosis. The permeabilization of mitochondrial outer membrane is regulated by $\mathrm{Bcl}-2$ family proteins and it can bind selectively to the active conformation of Bax to prevent it from inserting into the mitochondrial outer membrane to maintain the normal permeability of membrane permeable transition pores and prevent the release of mitochondrial pro-apoptotic factors, such as cytochrome c, AIF and Smac/DIABLO [21-24]. In our previous study, we found significant changes in p38 and $\mathrm{p} 53$ activation in combination of $\mathrm{IR}+\mathrm{mAbs}$ and it was associated with DNA strand breaks [6]. In association with activation of p38 and p53, Here, we found significant reduce in the expression of Bcl-2 and up-regulation of Bax expression in radiation alone or in combinations $(\mathrm{IR}+\mathrm{mAbs})$ as compared to un-irradiated or untreated control (Figures $1 \mathrm{~A}$ and $1 \mathrm{~B})$. Interestingly, $\mathrm{Bax} / \mathrm{Bcl}-2$ ratio was found to be higher $\left({ }^{\star *} \mathrm{p}<0.01\right)$ in cells treated at $+20 \mathrm{hrs}$ post $1.5 \mathrm{~Gy}$ radiation exposure as compared to antibodies treated alone. In our previous study, we were found significant activation of caspase- 3 and higher levels of cleaved PARP in association with deferential levels of CD20 expression [6].

In addition, anti-CD20 mAbs also had the ability to change expression of major pro-survival pathways such as ERK1/2 MAPK, NF- $\mathrm{KB}$ and Akt $[14,15]$. These directly or indirectly play important role in regulation of pro-apoptotic and anti-apoptotic machinery. Thus, we also investigated whether Rtx or Tst mediated changes the expression of RelA and Akt expression. Cells treated with both Rtx and Tst separately showed significant changes $(\$ p<0.001)$ in the expression of two major cell survival pathways viz RelA and Akt (Figures 2A and 2B). Moreover, cells treated with Rtx or Tst at +20 hrs post 0.5 Gy or 1.5 Gy radiation exposure showed significant changes $\left({ }^{*} \mathrm{p}<0.05\right)$ in the expression of both RelA and Akt level, which participate in downregulation of Bcl-2 in Burkitt's lymphoma cell line 'Daudi'.

Our above observations revealed that treatment of cells with either Rtx or Tst at differential levels of CD20 on cell surface, preferentially reduce the expression of the anti-apoptotic gene product Bcl-2 and beside up-regulate the expression of pro-apoptotic gene product Bax. Simultaneously, we found anti-CD20 mAbs mediated changes in expression of pro-survival signaling protein RelA and Akt, which directly or indirectly controlled $\mathrm{Bax} / \mathrm{Bcl}-2$ ratio as shown in schematic Figure 3.

\section{Conclusion}

Present studies suggested that the efficacy of anti-CD20 mAbs is associated with CD20 levels on the cell surface. In conclusion, this report provides evidence that CD20 expression can be induced using low dose $\gamma$-radiation and improves antibody-mediated cell death during cancer immunotherapy. Therefore, use of low dose of radiation just prior to immunotherapy may be beneficial for the eradication of B-cell malignancy. These results may be useful to establish a theoretical basis to improve the efficacy of immunotherapy/radio-immunotherapy in case of cells expressing low surface levels of CD20.

\section{Acknowledgments}

The author is grateful to UGC for the award of research fellowship. We are also thankful to Director, INMAS for providing an opportunity to carry out this research work, Ms. Anjali Sharma for her help and support during radiation exposure of cells at Bhabhatron II Irradiation facility.

\section{Author Contributions}

Conceived and designed the experiments: Vijay Singh and Damodar Gupta Performed the experiments: Vijay Singh. Analyzed the data: Vijay Singh, Damodar Gupta. Contributed reagents/materials/analysis tools: Damodar Gupta, Wrote the paper: Vijay Singh and Damodar Gupta.

\section{References}

1. Manshouri T, Do KA, Wang X, Giles FJ, O'Brien SM, et al. (2003) Circulating $\mathrm{CD} 20$ is detectable in the plasma of patients with chronic lymphocytic leukemia and is of prognostic significance. 101: 2507-2513.

2. Lundin J, Osterborg A (2004) Advances in the use of monoclonal antibodies in the therapy of chronic lymphocytic leukemia. Semin Hematol. 41: 234-245.

3. Golay J, Lazzari M, Facchinetti V, Bernasconi S, Borleri G, et al. (2001) CD20 levels determine the in vitro susceptibility to rituximab and complement of B-cell chronic lymphocytic leukemia: further regulation by CD55 and CD59. Blood. 98: 3383-3389

4. Huhn D, von Schilling C, Wilhelm M, Ho AD, Hallek M, et al. (2001) Rituximab therapy of patients with B-cell chronic lymphocytic leukemia. Blood. 98: 13261331.

5. Tsai PC, Hernandez-llizaliturri FJ, Bangia N, Olejniczak SH, Czuczman MS (2012) Regulation of CD20 in rituximab-resistant cell lines and B-cell nonHodgkin lymphoma. Clin Cancer Res.18: 1039-1050.

6. Singh V, Gupta D, Arora R, Tripathi RP, Almasan A, et al (2014) Surface levels of CD20 determine anti-CD20 antibodies mediated cell death in vitro. PLoS One. 9: e111113.

7. Hofmeister JK, Cooney D, Coggeshall KM (2000) Clustered CD20 induced apoptosis: src-family kinase, the proximal regulator of tyrosine phosphorylation, calcium influx, and caspase 3-dependent apoptosis. Blood Cells Mol Dis. 26: 133-43. 
Citation: Singh V, Gupta D (2018) Differential Action of Anti-CD20 Monoclonal Antibodies: Role in Induction of Cell Death. J Cancer Sci Ther 10: 064068. doi: $10.4172 / 1948-5956.1000519$

8. Deans JP, Schieven GL, Shu GL, Valentine MA, Gilliland LA, et al. (1993) Association of tyrosine and serine kinases with the B cell surface antigen CD20. Induction via CD20 of tyrosine phosphorylation and activation of phospholipase C-gamma 1 and PLC phospholipase C-gamma 2. J Immunol. 151: 4494-4504.

9. Susin SA, Lorenzo HK, Zamzami N, Marzo I, Snow BE, et al. (1993) Molecular characterization of mitochondrial apoptosis-inducing factor. Nature. 397: 441-446.

10. Adams JM, Cory S (1998) The Bcl-2 protein family: arbiters of cell survival. Science. 281: 1322-1326

11. Mcllwain DR, Berger T, Mak TW (2013) Caspase functions in cell death and disease. Cold Spring Harb Perspect Biol 5: a008656.

12. Parrish AB, Freel CD, Kornbluth $S$ (2013) Cellular mechanisms controlling caspase activation and function. Cold Spring Harb Perspect Biol.

13. Rahman MA (2013) Caspase-family and apoptosis: an overview of therapeutic targets in cancer treatment.

14. Suzuki E, Umezawa K, Bonavida B (2007) Rituximab inhibits the constitutively activated PI3K-Akt pathway in B-NHL cell lines: involvement in chemosensitization to drug-induced apoptosis. Oncogene. 26: 6184-6193.

15. Bonavida B (2007) Rituximab-induced inhibition of antiapoptotic cell survival pathways: implications in chemo/immunoresistance, rituximab unresponsiveness, prognostic and novel therapeutic interventions. Oncogene. 26: 3629-3636.

16. Singh V, Gupta D, Arora R (2015) NF-kB as a key player in regulation of cellular radiation responses and identification of radiation countermeasures.

17. Singh V, Gupta D, Kalra N, Tripathi R (2014) The y-radiation induced CD20 expression and anti-CD20 antibodies mediated cell death on hematopoietic cancer cell. In: Proceedings of thirteenth annual meeting of the Society for Free Radical Research-India and international conference on recent trends in free radical and antioxidant research

18. Bradford MM (1976) A rapid and sensitive method for the quantitation of microgram quantities of protein utilizing the principle of protein-dye binding Anal Bio chem 72: 248-254.

19. Singh V, Gupta D, Almasan A (2015) Development of Novel Anti-Cd20 Monoclonal Antibodies and Modulation in Cd20 Levels on Cell Surface: Looking to Improve Immunotherapy Response. J Cancer Sci Ther. 7: 347-358.

20. Gupta D, Crosby ME, Almasan A, Macklis RM (2008) Regulation of CD20 expression by radiation-induced changes in intracellular redox status. Free Radical Biology and Medicine. 44: 614-623.

21. Lu CX, Fan TJ, Hu GB, Cong RS (2003) Apoptosis-inducing factor and apoptosis. 35: 881-885.

22. Fan TJ, Xia L, Han YR (2001) Mitochondrion and Apoptosis 33: 7-12.

23. Garrido C, Galluzzi L, Brunet M, Puig PE, Didelot C, (2006) Mechanisms of cytochrome c release from mitochondria. Cell Death Differ. 13: 1423-1433.

24. Green DR, Kroemer G (2004) The pathophysiology of mitochondrial cell death Science 305: 626-629. 